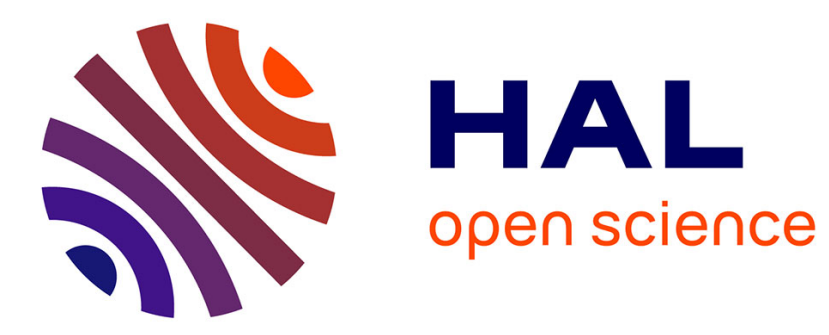

\title{
Rapid oscillations in Vostok and GRIP ice cores
}

\author{
P. Yiou, J. Jouzel, S. Johnsen, Ö. Rögnvaldsson
}

\section{To cite this version:}

P. Yiou, J. Jouzel, S. Johnsen, Ö. Rögnvaldsson. Rapid oscillations in Vostok and GRIP ice cores. Geophysical Research Letters, 1995, 22 (16), pp.2179-2182. 10.1029/95GL02014 . hal-03334868

\section{HAL Id: hal-03334868 \\ https://hal.science/hal-03334868}

Submitted on 5 Sep 2021

HAL is a multi-disciplinary open access archive for the deposit and dissemination of scientific research documents, whether they are published or not. The documents may come from teaching and research institutions in France or abroad, or from public or private research centers.
L'archive ouverte pluridisciplinaire HAL, est destinée au dépôt et à la diffusion de documents scientifiques de niveau recherche, publiés ou non, émanant des établissements d'enseignement et de recherche français ou étrangers, des laboratoires publics ou privés. 


\title{
Rapid oscillations in Vostok and GRIP ice cores
}

\author{
P. Yiou and J. Jouzel ${ }^{1}$ \\ Laboratoire de Modelisation du Climat et de l'Environnement, CEA-DSM, CE Saclay
}

\section{S. Johnsen ${ }^{2}$ and Ö. E. Rögnvaldsson}

The Niels Bohr Institute of Astronomy, Physics and Geophysics, Department of Geophysics, University of Copenhagen

\begin{abstract}
We investigate the spectral properties of climatic times series derived from two recent ice cores in Greenland and East Antarctica. We find that the signals behave in a similar way in the high frequency part of their spectra. The rapid oscillations found in the GRIP ice core were closely correlated to Heinrich Events. A comparable spectral feature is detected in the Vostok ice core. We discuss the possibilities of connections between the two hemispheres and proper ice sheet oscillations in the light of simple oscillating climate models.
\end{abstract}

\section{Introduction and Motivation}

Two recent ice cores drilled in Greenland (GRIP) and Antarctica (Vostok) provide a wealth of information on the climate variations in both hemispheres over the last climatic cycle. We show how the analyses of their spectral common features and differences provide hints on the major mechanisms that caused their variability.

The Greenland ice core [GRIP Project Members, 1993] reached a depth of $3028 \mathrm{~m}$, near the bedrock, at Dome Summit. A $\delta^{18} \mathrm{O}$ record was recovered, testifying for past local temperature variations [Johnsen et al., 1992]. The top of the core was dated with annual stratigraphy; the bottom was dated with a glaciological model, with a quantitative agreement with North Atlantic marine cores. With this chronology, it spans $230 \mathrm{kyr}$ BP (kyr: kilo year; BP: before present) with an average sampling interval of $0.2 \mathrm{kyr}$. We restrict the interpretation of our spectral results to the $115 \mathrm{kyr}$ top part of the core, where the differences with the sister core GISP2 are still minor [Grootes et al., 1993].

The Vostók ice core was đinlled in East Antarctica and reaches a depth of $2546 \mathrm{~m}$. The chronology was established upon an ice-flow model accounting for variable accumulation with time [Jouzel et al., 1993]. It is slightly different from the chronology of Lorius et al. [1985] but it reduces the discrepancy with marine stage 5 during the last interglacial.

\footnotetext{
'Also at Laboratoire de Glaciologie et Geophysique de l'Environnement, CNRS, BP 96, 38402 St. Martin d'Heres, France.

${ }^{2}$ Also at Science Institute, University of Iceland, IS-107, Reykjavik, Iceland.
}

Copyright 1995 by the American Geophysical Union.

Paper number 95GL02014

0094-8534/95/95GL-02014\$03.00
Thus the Vostok time series reaches $220 \mathrm{kyr}$ BP with an average time sampling of $0.1 \mathrm{kyr}$. Deuterium content was analyzed to reconstruct past local temperature variations [Jouzel and Merlivat, 1984].

Since the pioneering work of Hays et al. [1976], evidences for the orbital forcing of climate have been found in many paleo-data sets, including the Vostok and GRIP ice cores [Jouzel et al., 1987; Johnsen et al., 1992]. Higher frequencies have been documented in marine cores and ice cores, on time scales between 2 and 12 kyr [Pestiaux et al., 1988; Yiou et al., 1991; Hagelberg et al., 1994]. The fine sampling of those ice cores reveals the multiple time scales of paleoclimate variations. This motivated the elaboration of a working frame to discriminate slow "external" orbital variations from rapid "internal" climatic oscillations.

\section{Methodology}

We used several signal-processing techniques, to unravel the different aspects of the variability contained in the records. We emphasize the necessity of using different techniques and varying their parameters, in order to reduce the risks of spurious results and enhance their reliability.

We use a multi-taper method (MTM: Thomson [1982]) to estimate the total power spectrum of a time series, and determine its line frequencies by harmonic analysis. MTM is designed to reduce the variance of spectral estimates and is particularly well adapted to analyze short time series.

We apply singular-spectrum analysis (SSA) [Broomhead and King, 1986; Vautard and Ghil, 1989] to decompose time series into trends, oscillations and noise. SSA is designed to reconstruct parts of the underlying dynamics of a time series, without prior knowledge of the equations that generated it, by using embedding techniques [Vautard et al., 1992].

The wavelet decomposition is designed to study the timefrequency variations of a time series [Farge, 1992], so that transient or intermittent components can be detected efficiently, because the analyzing functions (using a Morlet wavelet) are localized both in time and frequency. In comparison, a classic Fourier analysis spreads the singularities of a time series over the entire power spectrum, creating spurious peaks or concealing real ones, unless an evolutive spectral analysis is performed [Yiou et al., 1991]. A wavelet analysis decomposes a time series into scale components, to discriminate between fast (time) scale oscillations and others at slow scales. In our graphical representations, the wavelet transform of a purely periodic signal would be a ridge at a constant scale. 
MTM and SSA require time series with a constant time step. We interpolated both data sets at various intervals between $0.2 \mathrm{kyr}$ to $1 \mathrm{kyr}$, to ensure the stability of our results. We also used several methods for interpolation [Yiou, 1994]: i) spline and linear interpolation, ii) averaging interpolation, i.e., by computing series averages over each constant time interval, iii) using the depth-time relationship, with an almost constant sampling in depth. Our results are robust to those schemes, up to frequencies of $\approx 1 / 4$ cycles $/ \mathrm{kyr}$.

\section{Results}

MTM spectral analyses of both data sets exhibit variability near the conspicuous Milankovitch cycles [Berger, 1977], at $41 \mathrm{kyr}$ (Vostok) and $23 \mathrm{kyr}$ (GRIP), superimposed on a colored and quasi-continuous power spectrum (figures 1 and 2). These results point to the orbitally-forced nature of paleoclimate variations on long time scales (over $115 \mathrm{kyr}$ ), given the relative shortness of the time series compared to the orbital periods. The Vostok ice core yields a stronger obliquity component, whereas the GRIP ice core contains important precessional cycles. This shows that, within the accuracy of the chronologies, both cores are differently influenced by the astronomical forcing. This "low frequency" variability is captured by the first few SSA principal components (PC\#15 in Vostok and PC\#1-4 in GRIP) and can be removed from both time series without altering the other dynamical components of the signals. Those reconstructed components also contain cycles between $10 \mathrm{kyr}$ and $15 \mathrm{kyr}$ of period, which can be related to low order harmonics of orbital cycles [Yiou et al., 1991; Hagelberg et al., 1994].

When the low frequency components are removed from both time series, we find a significant range of variability in the frequency band of $1 / 4$ to $1 / 8$ cycles/kyr with MTM and SSA. The Vostok core shows a stable average peak frequency near $1 / 6.7$ cycles/kyr (figure 1), while the GRIP core has an average frequency of $1 / 5.2$ cycles/kyr (figure 2). These two features are stable when the sampling intervals (from $0.2 \mathrm{kyr}$ to $1 \mathrm{kyr}$ ), the MTM parameters, and the length of the time

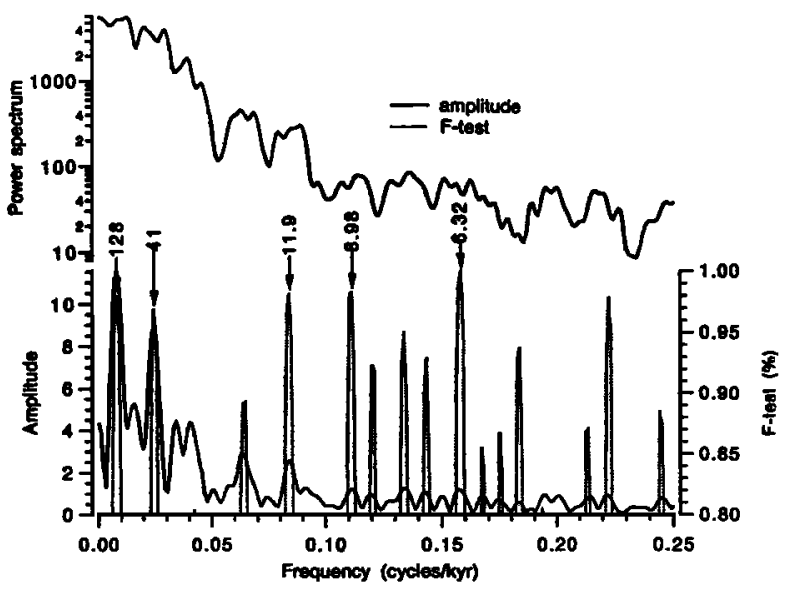

Figure 1. MTM analysis of the Vostok time series. The upper panel shows the power spectral estimate, using a bandwidth $W . N=2$ and 3 tapers. The lower panel shows the harmonic analysis of the time series. The solid line represents the line amplitudes and the dotted line represents the confidence $F$-test. The numbers above the arrows show the most stable peaks with high $F$-test.

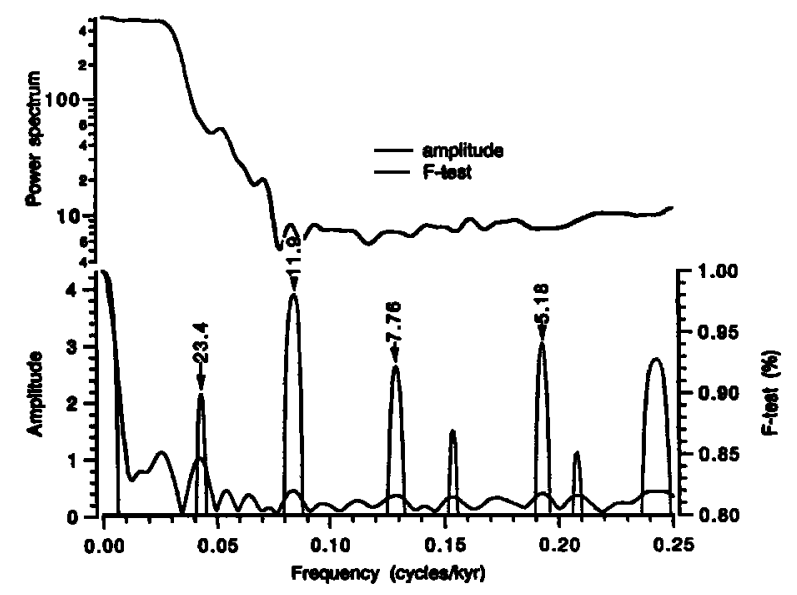

Figure 2. MTM analysis of the GRIP ice core for the $115 \mathrm{kyr}$ top part. The MTM bandwidth is $W . N=4$ and 7 tapers were used. The caption is the same as in Figure 1.

series are varied. In both cases, these frequencies reveal oscillation patterns found with SSA analysis (figure 3), with comparable relative amplitudes with respect to the total variations. These oscillations correspond to pairs of eigenvalues in SSA which occur just after the orbitally-forced parts of the singular spectra and indicate the presence of a (possibly nonlinear) oscillator in the system that generated a time series [Vautard et al., 1992]. The oscillations yield irregular amplitudes along both cores, but they are closely related to a similar behavior in other marine cores [Yiou et al., 1994]. A parallel investigation [Mayewski et al., 1994] on the GISP2 record of chemical species reveals a comparable oscillation.

Wavelet analyses confirm the similarity of oscillation patterns in both cores with smaller scales (or higher frequencies) in the GRIP ice core (figures 4 and 5). They show the highly non-stationary features of climatic variations on that time scale, as no constant-scale (horizontal) features are detected on the modulus plots.

\section{Discussion}

Our results clearly depend on the chronology hypotheses. Comparison experiments [Waelbroeck et al., 1995] show that the Vostok time scale is accurate within $10 \%$ down to $120 \mathrm{kyr}$

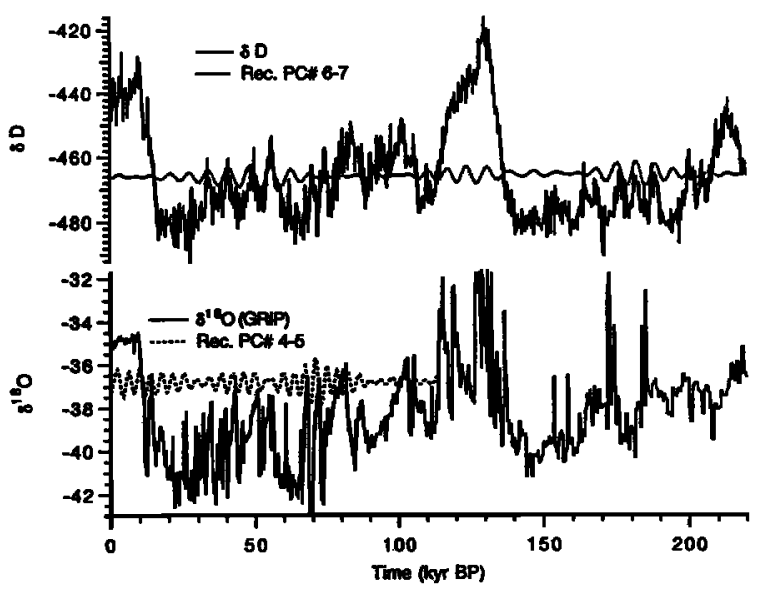

Figure 3. $\delta \mathrm{D}$ and $\delta^{18} \mathrm{O}$ variations at Vostok and GRIP (solid lines). The dotted lines represent reconstructed components from two pairs of SSA eigen-elements. The time series were interpolated every $0.5 \mathrm{kyr}$ and the dimension of the augmented vectors was taken as $M=40$. 


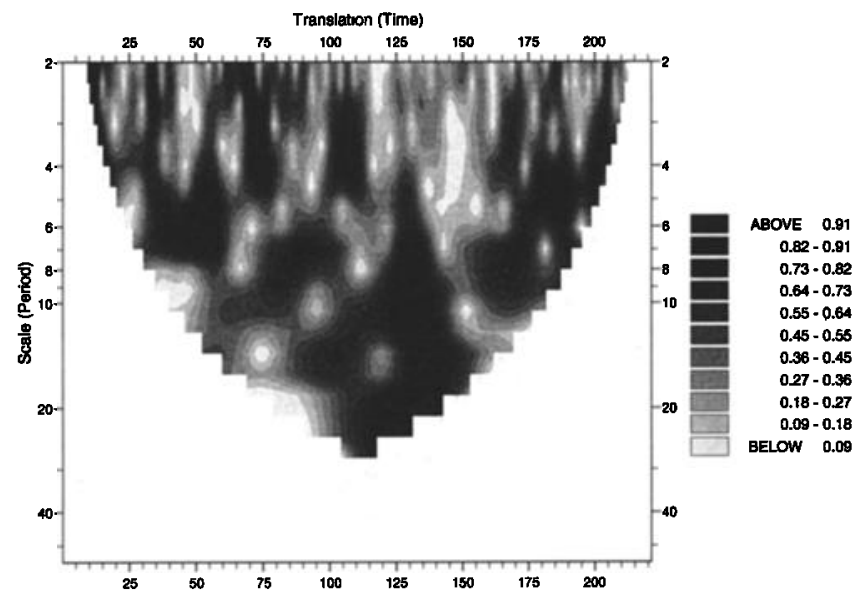

Figure 4. Modulus level chart of a wavelet transform of the Vostok deuterium time series. The horizontal axis is translation (time) and the vertical axis is the scale parameter (period). The modulus was normalized to enhance the high frequency (small scale) features. The plots were truncated in order to avoid spurious side effects. The scale band around $6 \mathrm{kyr}$ corresponds to the SSA reconstruction of PCs 6 and 7, and the local maxima of the wavelet plot are consistent with the oscillations of this reconstruction (e.g. near $50 \mathrm{kyr} \mathrm{BP}$ ).

BP. With this caveat in mind, we propose interpretations of the spectral results.

The rapid oscillations in the GRIP core were correlated to the Heinrich events [Heinrich, 1988; Broecker et al., 1992] in a North Atlantic deep sea core [Bond et al., 1993]; this suggests a global pattern of oscillation which can also occur in the Southern hemisphere. Those events are characterized by sudden and massive iceberg surges into the North Atlantic. They would have slown down the thermohaline circulation, implying a cooling in the northern hemispheric high latitudes, recorded in the ice [Bond et al., 1993]. As the ice margins retreat on the continent, the input of fresh water stops and the thermohaline circulation can resume again, implying a sudden warming of the northern latitudes. Because this mechanism is quasi-cyclic [Paillard and Labeyrie, $1994]$, it can be speculated that the $\approx 5.1 \mathrm{kyr}$ oscillation and its amplitude, found in the GRIP ice core, are symptomatic of the succession of those glacial oscillations. Other scenarios of ice sheet variability are also plausible and provide the same range of periodicity [Ghil and Le Treut, 1981].

At Vostok, the average period of the oscillation is slightly larger. From the correlation of these oscillations we propose two scenarios. First, climate changes, linked to massive input of freshwater, can propagate to the southern hemisphere, through a reduced Atlantic thermohaline circulation due to sea surface salinity anomalies [Weaver et al., 1993], thus changing the meridional energy budget and the climate in Antarctica [Bender et al., 1994]. This implies that glacialage climatic changes are solely driven by the northern hemisphere. This teleconnection scenario requires a high correlation between identified events in the cores, and efficient global stratigraphic markers such as $\delta^{18} \mathrm{O}$ of air trapped in the ice down to $133 \mathrm{kyr}$ BP [Sowers et al., 1993]. We made spectral analyses of the Vostok deuterium record with a chronology derived from a correlation between the SPECMAP levels and the $\delta^{18} \mathrm{O}$ in the air bubbles in the Vostok ice core [Sow- ers et al., 1993]. The results tend to lower the periodicities found in the Vostok time series and to "tune" the peak ones around $\mathrm{a} \approx 5.1 \mathrm{kyr}$ period; the presence of $\mathrm{a} \approx 6.7 \mathrm{kyr}$ period is still significant, but the time correlation obviously reduces the spectral discrepancy between the cores, keeping the same qualitative features in the spectra.

Second, evidences of recurring massive iceberg surges have also been reported [Shemesh et al., 1994] in the Southern Oceans during the last ice age; such oscillations were also predicted by a model of the West Antarctic ice sheet [MacAyeal, 1992]. It is thus possible that the same "Heinrich type" dynamics occurred in both hemispheres [Verbitsky and Saltzman, 1995] and imprinted in the Vostok $\delta \mathrm{D}$ record. The difference in amplitude would be due to the fact that the Vostok site is far from coastal areas and that the Antarctic circumpolar current dispatches icebergs in the Indian and the Pacific, as well as in the Atlantic Ocean, hence attenuating its local effects. The close synchroneity of the ice age events in both hemispheres can be explained by the sea level changes destabilizing ice shelves (either in the Northern or the Southern hemisphere). In this case, during an ice age, the climatic system would contain two ice sheet oscillators coupled through the sea level and, to some extent, the thermohaline circulation. Such systems have their own modes of oscillations but the period difference does not exceed $1 \mathrm{kyr}$ as the ocean coupling keeps them in phase.

\section{Conclusion}

We have examined how the rapid oscillations observed in the Vostok and GRIP ice cores can be related to ice sheet fluctuations in both hemispheres. Recent data the Southern oceans reporting massive glacial surges from the Antarctic ice sheet from [Shemesh et al., 1994] confirm the idea of two coupled glacial oscillators. Evidently, more data are needed to verify this assertion, in particular on the exact pattern of temperature variations around Antarctica and on the strength of the southern thermohaline activity during those events.

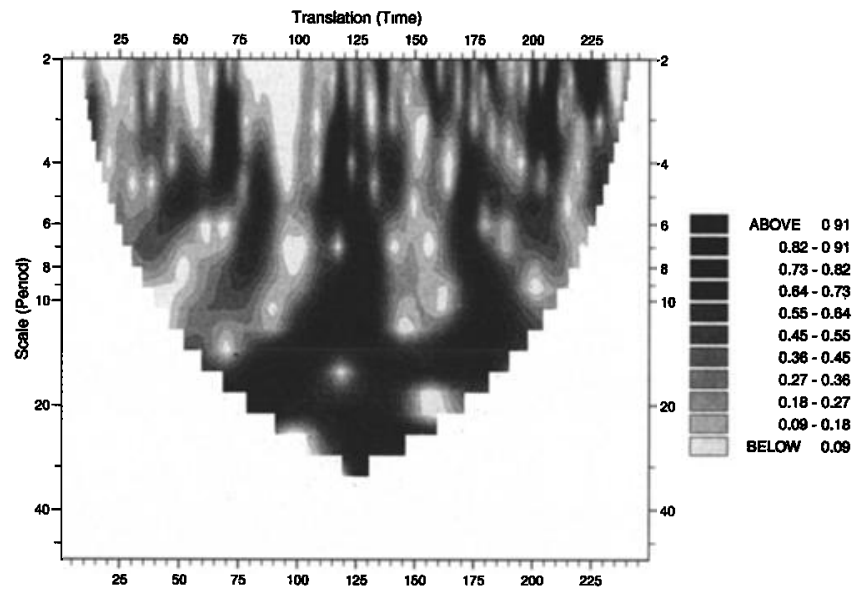

Figure 5. Modulus level chart of a wavelet transform of the GRIP deuterium time series. The entire time series (230 kyr) was analyzed, because the global picture is unaffected by possible glaciological problems past $120 \mathrm{kyr}$ BP. Local amplitude maxima (darker scale) occur at the same translation times as in the Vostok wavelet analysis, i.e., $50 \mathrm{kyr}, 75 \mathrm{kyr}$, $125 \mathrm{kyr}$ and $175 \mathrm{kyr} \mathrm{BP}$, although with smaller scales in the GRIP time series, explaining the smaller average period in GRIP. The scale band around $5 \mathrm{kyr}$ is consistent with the SSA pair reconstruction $(4,5)$, with matching maxima. 
In a broader perspective, our results demonstrate the power of those mathematical tools in decomposing the dynamical features of time series and enhancing the possibilities to compare them. Thus, it was possible to extract a common dynamical behavior between the GRIP and Vostok ice cores, despite the fact that they answer differently in the orbital domain. This result enables to constrain the variability patterns of future global time-dependent models of climate.

Acknowledgments. This work is a contribution to the Greenland Ice-core Project (GRIP) organized by the European Science Foundation, and the Vostok Project. We thank the GRIP and Vostok participants and supporters for their cooperative effort. We also acknowledge the national science foundations in Belgium, Denmark, France, Germany, Iceland, Italy, Switzerland and the United Kingdom, and the XII Directorate of CEC, the Carlsberg Foundation and the Commision for Scientific Research in Greenland for financial support. It is pleasure to thank M. Bender and P. Mayewski for valuable discussion, and T. Sowers for sharing the Vostok chronology from $\delta^{18} \mathrm{O}$ of air bubbles.

\section{References}

Bender, M., et al. (1994). Climate correlations between Greenland and Antarctica during the past 100,000 years. Nature, 372:663666.

Berger, A. (1977). Support for the astronomical theory of climatic change. Nature, 269:44-45.

Bond, G., et al. (1993). Correlations between climate records from North Atlantic sediments and Greenland ice. Nature, 365: 143147.

Broecker, W. S., Bond, G., Klas, M., Clark, E., and McManus, J. (1992). Origin of the northern Atlantic's Heinrich events. Clim. Dyn., 6:265-273.

Broomhead, D. S. and King, G. P. (1986). Extracting qualitative dynamics from experimental data. Physica, D20:217-236.

Farge, M. (1992). Wavelet transforms and their applications to turbulence. Ann. Rev. Fluid Mech., 24:395-457.

Ghil, M. and Le Treut, H. (1981). A climate model with cryodynamics and geodynamics. J. Geophys. Res., 86(C6):5262-5270.

GRIP Project Members (1993). Climatic instability during the last Interglacial period recorded in the GRIP ice core. Nature, 364:203-207.

Grootes, P. M., Stuiver, M., White, J. W. C., Johnsen, S., and Jouzel, J. (1993). Comparison of oxygen isotope records from the GISP2 and GRIP Greenland ice cores. Nature, 366:552-554.

Hagelberg, T. K., Bond, G., and deMenocal, P. (1994). Milankovitch band forcing of sub-Milankovitch climate variability during the Pleistocene. Paleoceanography, 9(4):545-558.

Hays, J. D., Imbrie, J., and Shackleton, N. J. (1976). Variations in the Earth's orbit: Pacemaker of the ice ages. Science, 194:11211132.

Heinrich, H. (1988). Origin and consequences of cyclic ice-rafting in the northeast Atlantic Ocean, during the past 130,000 yrs. Quat. Res., 29:143-152.

Johnsen, S. J., et al. (1992). Irregular glacial interstadials recorded in a new Greenland ice core. Nature, 359:311-313.

Jouzel, J., et al. (1993). Extending the Vostok ice-core records of palaeoclimate to the penultimate glacial period. Nature, 364:407-412.
Jouzel, J., et al. (1987). Vostok ice core: a continuous temperature record over the last climatic cycle $(160,000$ years). Nature, 329:403-408.

Jouzel, J. and Merlivat, L. (1984). Deuterium and oxygen 18 in precipitation: Modeling of the isotopic effects during snow formation. J. Geophys. Res., 89:11749-11757.

Lorius, C., et al. (1985). A 150,000 year climatic record from Antarctic ice. Nature, 316:591-596.

MacAyeal, D. R. (1992). Irregular oscillations of the West Antarctic ice sheet. Nature, 359:29-32.

Mayewski, P. A., et al. (1994). Periodic behavior in atmospheric circulation over the last 110,000 years deduced from a Greenland ice core. Science, (submitted).

Paillard, D. and Labeyrie, L. D. (1994). Role of the thermohaline circulation in the abrupt warming after Heinrich events. Nature, 372: 162-164.

Pestiaux, P., Van Der Mersch, I., Berger, A. L., and Duplessy, J.C. (1988). Paleoclimatic variability at frequencies ranging from 1 cycle per 10,000 years to 1 cycle per 1000 year: evidence for nonlinear behaviour of the climate system. Climatic Change, 12:9-37.

Shemesh, A., Burckle, L. H., and Hays, J. D. (1994). Meltwater input to the southern ocean during the last glacial maximum. Science, 266: 1542-1544.

Sowers, T., et al. (1993). A 135,000-year Vostok-SPECMAP common temporal framework. Paleoceanography, 8:737-766.

Thomson, D. J. (1982). Spectrum estimation and harmonic analysis. IEEE Proc., 70(9): 1055-1096.

Vautard, R. and Ghil, M. (1989). Singular spectrum analysis in nonlinear dynamics, with applications to paleoclimatic time series. Physica, D35:395-424.

Vautard, R., Yiou, P., and Ghil, M. (1992). Singular spectrum analysis: a toolkit for short noisy chaotic signals. Physica, D58:95126.

Verbitsky, M. and Saltzman, B. (1995). A diagnostic analysis of Heinrich glacial surge events. Paleoceanography, 1:59-65.

Waelbroeck, C., et al. (1995). Comparing the Vostok ice deuterium record and series from Southern Ocean core MD88-770 over the last two glacial-interglacial cycles. Clim. Dyn. (accepted).

Weaver, A. J., Marotzke, J., Cummins, P. F., and Sarachik, E. S. (1993). Stability and variability of the thermohaline circulation. J. Phys. Oceanogr., 23:39-60.

Yiou, P. (1994). Dynamique du Paléoclimat: Des Données et des Modèles. PhD thesis, Université Pierre et Marie Curie, Paris 6.

Yiou, P., et al. (1991). High-frequency paleovariability in climate and in $\mathrm{CO}_{2}$ levels from Vostok ice-core records. J. Geophys. Res., 96(B12):20365-20378.

Yiou, P., Ghil, M., Jouzel, J., Paillard, D., and Vautard, R. (1994). Nonlinear variability of the climatic system, from singular and power spectra of Late Quaternary records. Clim. Dyn., 9:371389.

S. Johnsen and Ö. E. Rögnvaldsson, The Niels Bohr Institute of Astronomy, Physics and Geophysics, Department of Geophysics, University of Copenhagen, Haraldsgade 6, DK-2200. Denmark.

J. Jouzel and P. Yiou, Laboratoire de Modelisation du Climat et de l'Environnement, DSM. CE Saclay, l'Orme des Merisiers. 91191 Gif-sur-Yvette. France. (email: pyiou@cea.fr)

(received Feb. 02, 1995; revised May 05, 1995; accepted June 05, 1995.) 